\title{
Community pharmacy: an innovative way to deliver cancer survivorship interventions
}

Agnieszka Lemanska ${ }^{1}$, Karen Poole ${ }^{1}$, Bruce A. Griffin², Ralph Manders², John Saxton ${ }^{3}$, Kerri M. Winters-Stone ${ }^{4}$, Sara Faithfull $^{1}$

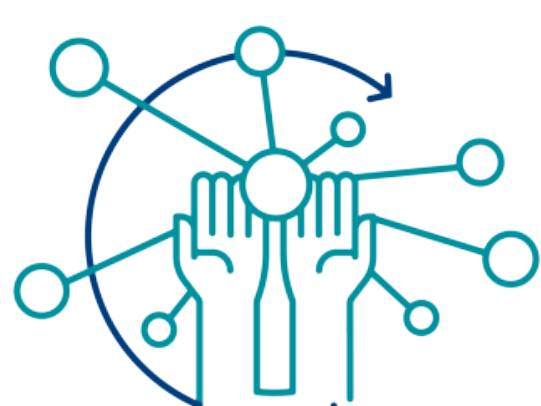

NIVERSITY OF SURREY

Cancer Care

1 University of Surrey, School of Health Sciences, Guildford, United Kingdom.

${ }^{2}$ University of Surrey, School of Bioscience and Medicine, Guildford, United Kingdom.

${ }^{3}$ Northumbria University, Faculty of Health and Life Sciences, Newcastle Upon Tyne, United Kingdom.

${ }^{4}$ Oregon Health and Science University, Schools of Nursing, Portland, USA.

\section{Background}

Prostate cancer and its treatment can have a negative impact on men's health and quality of life.

Despite evidence of the benefits of physical activity, only $10-32 \%$ of people living with and beyond cancer in the UK engage at recommended physical activity levels.

Lifestyle interventions are of particular importance given the potential risk of cardiovascular disease associated with Androgen Deprivation Therapy (ADT) used to treatment prostate cancer

Community pharmacies have potential for providing local cancer survivor support services

\section{Method}

This pharmacy-led health and physical assessment and lifestyle intervention provided a lifestyle prescription using a computerised algorithm. This was repeated at 3 months and supported by 2 phone calls and instructional materials.

Eligibility criteria: included men with non metastatic prostate cancer, who had completed treatment and had at least one of three risk factors: underweight, overweight or obese, ADT, and or hypertension.

Outcome measures: Physical activity and quality of life were assessed at baseline, 3 and 6 months, this included pre- and post-intervention assessments of physical activity (accelerometry) and patient reported outcomes (European Prostate Cancer Index Composite, EPIC-26; Euro QOL 5dimension, EQ5D-5L).

Research question: What is the feasibility and acceptability of a community pharmacy lifestyle intervention for improving physical activity and health related outcomes in men with prostate cancer?

\section{Results}

Recruitment: 403 men were eligible, $172(43 \%)$ responded and $116(29 \%)$ were recruited. We report $15 \%$ attrition as $99(85 \%)$ of men completed the intervention in 9 pharmacies from 3 different business models (large, chain, independent).

Outcomes at 3 months compared to baseline scores showed men's MVPA had increased by $34 \pm 152$ minutes $\mathrm{p}=0.018$, but was not sustained at 6 months (Table 1 ).

Although no statistically significant change was recorded in global quality of life at 6 months, there were a significant improvement in sexual and hormonal domains (Table 2).

Table 1. Change in accelerometry data during the community pharmacy lifestyle intervention
\begin{tabular}{|lrrrrrrrrrr|}
\hline \multicolumn{8}{|c|}{ Increase from baseline to three months } & Increase from baseline to six months \\
\hline & $\begin{array}{r}\text { Mean } \\
\text { change }\end{array}$ & $\begin{array}{r}\text { Lower } \\
95 \% \mathrm{Cl}\end{array}$ & $\begin{array}{r}\text { Upper } \\
95 \% \mathrm{Cl}\end{array}$ & $P$-value & $\begin{array}{r}\text { Mean } \\
\text { change }\end{array}$ & $\begin{array}{r}\text { Lower } \\
95 \% \mathrm{Cl}\end{array}$ & $\begin{array}{r}\text { Upper } \\
95 \% \mathrm{Cl}\end{array}$ & $P$-value \\
\hline $\begin{array}{l}\text { Counts per day } \\
\left(\begin{array}{l}1 \\
\text { MV00) }\end{array}\right.\end{array}$ & $3.3(48.3)$ & -5.6 & 12.2 & 0.466 & $\begin{array}{r}-4.6 \\
(72.7)\end{array}$ & -18 & 8.8 & 0.499 \\
$\begin{array}{l}\text { MVA per week } \\
\text { (minutes) }\end{array}$ & $34(152)$ & 6 & 62 & 0.018 & $14(220)$ & -27 & 54 & 0.509 \\
$\begin{array}{l}\text { MVPA in bouts } \geq \\
10 \text { minutes per } \\
\text { week (minutes) }\end{array}$ & $-2(59)$ & -12 & 9 & 0.756 & $3(70)$ & -9 & 16 & 0.603 \\
\hline
\end{tabular}

MVPA = Moderate to Vigorous Physical Activity

Table 2. Change in patient reported outcomes (PROs) as measured with EPIC-26

\begin{tabular}{|lrrrrrr|}
\hline EPIC-26 domains & $\begin{array}{r}\text { Baseline } \\
\mathrm{n}=114\end{array}$ & $\begin{array}{r}\text { months } \\
\mathrm{n}=91\end{array}$ & $\begin{array}{c}\text { Mean } \\
\text { change }\end{array}$ & $\begin{array}{r}\text { P-value } \\
\text { Lower 95\% }\end{array}$ & $\mathrm{Cl}$ & Cl \\
\hline Urinary Incontinence & 82.93 & 82.04 & 0.9 & 0.364 & -1.05 & 2.84 \\
Urinary Irritative / Obstructive & 88.4 & 88.72 & -0.32 & 0.692 & -1.94 & 1.29 \\
Bowel & 88.35 & 88.43 & -0.09 & 0.923 & -1.87 & 1.7 \\
Sexual & 20.72 & 23.6 & -2.89 & 0.012 & -5.11 & 0.66 \\
Hormonal & 73.39 & 76.77 & -2.8 & 0.006 & -4.8 & -0.8 \\
\hline
\end{tabular}

"It's a real learning experience for you as a pharmacist and it's a positive way to really show and help somebody in the community, it's a real positive thing."

\section{Conclusion}

Community pharmacy-based lifestyle intervention had benefits for men living with and beyond prostate cancer. The intervention was feasible and acceptable to men and could be delivered successfully in a commercial pharmacy model.

Community pharmacies were easy to access for men and pharmacy teams, who had the skills and confidence to complete the training and deliver the intervention.

Whilst this study provides evidence of the potential short-term benefits of physical activity and dietary intervention for men, to address comorbidities after prostate cancer treatment, meeting the MVPA guidance for physical activity still proved a challenge in 3 months. A further randomised controlled trial is needed to assess the effectiveness and relative cost-efficacy of community pharmacy models for supporting people living with and beyond a cancer diagnosis.

Lemanska A, Poole K, Griffin BA, Manders R, Saxton JM, Turner L, Wainwright J, Faithfull S (2019) Community pharmacy lifestyle intervention to increase physical activity and improve cardiovascular health of men with prostate cancer: a phase II feasibility study https://bmjopen.bmj.com/content/9/6/e025114.full 